Western Washington University

Western CEDAR

$11-2003$

\title{
Art for Democracy's Sake? Group Membership and Political Engagement in Europe
}

Todd Donovan

Western Washington University, todd.donovan@wwu.edu

Shaun Bowler

Robert Hanneman

Follow this and additional works at: https://cedar.wwu.edu/politicalscience_facpubs

Part of the Political Science Commons

\section{Recommended Citation}

Donovan, Todd; Bowler, Shaun; and Hanneman, Robert, "Art for Democracy's Sake? Group Membership and Political Engagement in Europe" (2003). Political Science Faculty Publications. 8.

https://cedar.wwu.edu/politicalscience_facpubs/ 8 


\section{CAMBRIDGE UNIVERSITY PRESS}

\section{Southern Political Science Association}

Art for Democracy's Sake? Group Membership and Political Engagement in Europe Author(s): Shaun Bowler, Todd Donovan and Robert Hanneman

Source: The Journal of Politics, Vol. 65, No. 4 (Nov., 2003), pp. 1111-1129

Published by: Cambridge University Press on behalf of the Southern Political Science Association Stable URL: http://www.jstor.org/stable/3449924

Accessed: 23/10/2014 17:05

Your use of the JSTOR archive indicates your acceptance of the Terms \& Conditions of Use, available at http://www.jstor.org/page/info/about/policies/terms.jsp

JSTOR is a not-for-profit service that helps scholars, researchers, and students discover, use, and build upon a wide range of content in a trusted digital archive. We use information technology and tools to increase productivity and facilitate new forms of scholarship. For more information about JSTOR, please contact support@jstor.org. 


\title{
Art for Democracy's Sake? Group Membership and Political Engagement in Europe
}

\author{
Shaun Bowler \\ University of California, Riverside \\ Todd Donovan \\ Western Washington University \\ Robert Hanneman \\ University of California, Riverside
}

\begin{abstract}
Theorists contend that private social groups-particularly those that have no overt political missions such as bowling leagues, sports clubs, and choral societies-make major contributions to democracy by generating engagement with democracy in the form of political interest and participation. Although this discussion is generally at an aggregate level, it is based on seldom-tested assumptions about individual-level phenomena. This study expands our understanding of how (and where) memberships in various groups are associated with political engagement of individual citizens. We test if the effects of group membership vary across eleven European democracies and test which types of groups have the strongest association with political engagement. We find that major social groups differ in their relationship with engagement, and we also find that formal political arrangements for group accommodation may condition the effects of some memberships on engagement.
\end{abstract}

he work of Robert Putnam has done much to reestablish the relevance of voluntary social groups and the potential role that these groups play in maintaining democratic practices (Putnam 1993, 1995; see also Norris 1996; Verba, Schlozman, and Brady 1995). The nub of this argument is well known: private civic associations-particularly those that have no overt political missions such as bowling leagues, sports clubs, and choirs - make major contributions to the building of politically relevant human and social capital (see also Almond and Verba 1963; Barber 1995, 281; Pateman 1970). Kim (2000) refers to this group of scholars as the neo-Tocquevillians.

Although social capital has often been discussed in terms of aggregate-level indicators, there are, or at least should be, clear individual-level implications of the phenomena. Yet, as Hooghe (1999) notes, there is surprisingly little empirical work on the individual-level effects of civic associations given how important they are held to be in the social science literature. Although we have individual-level models of people's interest in and engagement with politics, if

THE JOURNAL OF POLITICS, Vol. 65, No. 4, November 2003, Pp. 1111-1129

(c) 2003 Southern Political Science Association 
group membership is important then these models are underspecified in important ways. By the same token, if a focus on group membership and engagement with democratic politics ignores individual-level motivations for interest and activity then these models, too, may be underspecified and overstate the impact of group membership. One notable exception to a compartmentalized approach is that of Verba, Schlozman, and Brady (1995) who model political engagement in the United States as being driven by group membership, most importantly membership in church groups. As with the work by Putnam, this raises the question of how much we can generalize beyond the case of America. Specifically, does a model of political engagement that takes account of the effects of group membership "work" outside the United States, or are there amendments that need to be made? If the model is general and it does work across several nations, does it hold for all groups?

In this article we answer these questions by modelling political engagement in 11 European nations as a function of both individual-level attributes, including membership in groups, and national-level context. We do so using a hierarchical linear modelling (HLM) approach. Importantly, this approach allows us to take account of cross-national differences in the ways in which some groups are formally incorporated into the political system.

\section{Participation, Social Capital, and Political Engagement}

Arguments about the effects of social capital on democracy overlap with contemporary theories of participatory democracy that stress citizens are not isolated beings. Social organizations thus play an important "educative" role in teaching people how to tolerate each other, how to interact and work together, and how to act socially as well as politically. Such participation also provides them with a greater sense of efficacy and trust (Mansbridge 1980, 236; Pateman 1970, 42-46) and may make individuals more public spirited (Warren 1992, 8).

Coleman $(1990,302)$ advances similar propositions using the rubric of social capital - a macrolevel resource that enhances a polity's ability to act collectively. Putnam, in particular, stresses the importance of individual-level, nonpolitical participation as a means for providing the social capital that a nation needs to maintain healthy democratic practices. For Putnam (1993), participation in soccer clubs and choral groups, or, in the case of the United States, bowling as part of a league rather than solitary bowling, generates face-to-face interactions that build networks and trust, and over time, human capital. By joining social groups, citizens learn democratic norms and thus establish the basis for effective democratic practices. Social capital may also be built at the national level as citizens' networks of relations expand via participation in social groups.

One of the most thorough microanalyses of the impact of social groups is found in the civic voluntarism model of Verba, Schlozman, and Brady (1995). In addition to noting the impact of individual-level attributes such as education, income, and socialization processes, Verba et al. also highlight the importance of group 
and, in particular, church membership: "Running a rummage sale to benefit the church day care center or editing a church newsletter provides opportunities for the development of skills relevant to politics even though the enterprise is expressly non-political" (Verba, Schlozman, and Brady 1995, 383).

Central to the debates about the importance of voluntary membership in social groups is the causal proposition that membership produces democratic virtues of the kind noted above. However, although attempts have been made to refine the theories into clear causal statements, they have not yet been tested very thoroughly, especially within Europe (Hooghe 1999; Newton 1997). Extant studies that do attempt to advance causal propositions about determinants and effects of social capital typically focus on individual nations (for the United States, see Brehm and Rahn 1997; for Belgium, see Hooghe 1999; for Great Britain, see Moyser and Parry 1997; in contrast, see Booth and Richard 1998 on Central America). This research clearly advances our understanding of the effects of voluntary associations, yet most existing studies do not assess how these effects vary across types of groups and across established democracies that have different methods of incorporating citizens into the political system.

In addition, the question remains open as to whether some groups are better than others as incubators of democratic virtues or whether all groups are equally good in that regard. Putnam notes that Tocqueville wrote that "serious, futile, very general and very limited, immensely large and very minute" organizations alike would instil the habits of public spiritedness $(1993,90)$. Seemingly quite different groups, such as bowling leagues and choirs, are often lumped together as the kinds of associations that generate political engagement. The expectation seems to be that any group is just as good as any other, but this may not be the case. Some groups may be better at encouraging engagement than others. Labor unions, human rights organizations (Amnesty International), and environmental groups (Greenpeace), for example, have an obvious political dimension. It is not so obvious that sports groups (membership in a soccer club) or arts groups (choirs) have such a dimension.

\section{Variation in Group Effects and Variation in Institutional Context}

The question of whether there is likely to be variation in the impact of group membership is, typically, left unstated in this literature; however recent work has began to identify that groups differ in their internal diversity and in the solidarity they may breed. Stolle and Rochon observed different effects of group membership on trust and optimism in three nations, and cautioned that "a generalized enthusiasm for the effects of association membership must be tempered by a specification of what types of groups we are talking about" $(1998,57)$.

As Table 1 illustrates, there is substantial variation across European nations in the propensity for citizens to join voluntary associations and in the types that they join. The first column lists the percentage who reported membership in an at least one voluntary social group in 1990. Some of the groups (such as charities, arts, 
TABLE 1

Voluntary Group Membership in 12 European Nations

\begin{tabular}{lcccc}
\hline & \multicolumn{4}{c}{ Percentage of population who are members of: } \\
\cline { 2 - 5 } & $\begin{array}{c}\text { \% mentioning any } \\
\text { group (omitting } \\
\text { parties and unions) }\end{array}$ & $\begin{array}{c}\text { sports } \\
\text { group/club }\end{array}$ & $\begin{array}{c}\text { church- } \\
\text { based group }\end{array}$ & arts group/club \\
\hline Netherlands & 71.0 & 35.2 & 26.9 & 10.7 \\
Denmark & 70.5 & 34.8 & 20.9 & 10.3 \\
Great Britain & 54.6 & 23.8 & 19.4 & 6.8 \\
Ireland & 52.3 & 25.6 & 17.5 & 3.8 \\
Belgium & 51.0 & 21.9 & 8.9 & 14.0 \\
W. Germany & 49.2 & 27.9 & 15.9 & 4.9 \\
France & 38.5 & 16.1 & 6.2 & 6.3 \\
Italy & 31.6 & 10.2 & 8.8 & 6.5 \\
Spain & 23.2 & 8.3 & 5.9 & 3.3 \\
Portugal & 22.6 & 11.5 & 5.6 & 4.6 \\
Greece & 15.9 & 6.5 & 1.8 & 5.6 \\
\hline
\end{tabular}

Note: Cell entries are percentages of respondents claiming membership. The first column omits membership in political parties and labor unions, and includes church groups, arts groups, human rights groups, ecology groups, youth groups, consumer organizations, sports groups, and "other" social groups.

Source: Eurobarometer 34.0, November 1990.

and sports groups) have far less overt political content than others (such as consumer groups or human rights groups). According to these 1990 Eurobarometer \#34 data, the most common voluntary, nonpolitical groups that citizens join are sports groups. After sports clubs, unions, and church groups, the next most commonly cited membership was in arts groups. When memberships in unions and political parties are omitted, as with the data listed in Table 1, in most nations at least half of all voluntary group membership can be attributed to nonpolitical associations such as sports and arts groups, with much of the remaining balance being membership in church groups.

We test if memberships in various groups differ in their association with political engagement. These groups are not alike in how they bring people together, and not all social theorists are sanguine about the effects that certain voluntary social groups might have on democracy. Indeed, Kim (2000) illustrates that the groups Putnam identified as beneficial bred, for Max Weber, a passivity inimical to democracy. Sports clubs, in particular, constitute a category that likely captures a broad range of possible social interactions. Media images of European soccer fans do little to offer encouragement for the hypothesis that membership in such groups is associated with civic virtues. Even sports groups that require more active participation (i.e., playing sports versus simply watching or being a booster) may have questionable effects on civicness, since one of the primary social interactions that the group experiences is competition. In their study of 
voluntary associations in Germany, Sweden, and the U.S.A., Stolle and Rochon (1998) include sports clubs in the same category as hobby groups and car clubs, since these groups are organized around private, personal interests that are not expected to generate as much intragroup or intergroup trust and solidarity as other forms of association.

By contrast, one of the next largest categories of nonpolitical, voluntary group membership in Europe is arts clubs. As with sports groups, this category captures a wide range of variation in types of groups, including theatre groups, quilting bees, music performance groups, literary societies, choral groups, dance groups, folk art groups, and the like. There are also reasons to expect that participation in arts groups in particular would be associated with greater political engagement than sports clubs. Advocates of the arts claim that art plays a fundamental role in democratic societies by integrating minority ideas into the culture (Arian 1989; Blandy and Congdon 1987, 76). The arts also generate faceto-face contacts that might bridge cultural divides, while exposing people to a wider variety of experiences and ideas (Boyer 1987). Most importantly, much art that is not the least bit avant-garde requires a substantial degree of group effort and coordination built upon individual sacrifice and consensus (Arian 1989, 111). The product of interactions in arts groups is often public and, relative to sports groups, noncompetitive.

Another way in which the neo-Tocquevillian argument is incomplete is that it can be read as saying that a fluid, informal relationship between voluntary association and civil society is either the only or the best way of promoting democratic engagement. National-level political context, however, may play a role. Tarrow (1996) specifically criticizes Putnam for failing to recognize that the Italian state itself may have stimulated high levels of associational activity. Other scholars have faulted Putnam for failing to consider how a nation's political "rules of the game" shape civil society. Foley and Edwards (1996) stress the contextual effect of political repression on civil society in El Salvador, while Booth and Richard (1998) demonstrate that regime repression in Central America depressed individual-level trust, democratic norms, and political participation. Indeed, as Table 1 illustrates, nations with the most recent history of political repression (Portugal and Greece) have the lowest levels of reported group membership.

If levels of political engagement are tied to skills learned by the society as a whole via group activity, then these nations may have less of a base for creating engaged citizens. Although people residing in longer-lived democracies like Great Britain may have some very general sense of how to engage in politics, such learning may not be as well established in Portugal or Greece. Given this, we need to account for national-level effects on political engagement associated with whether a respondent lives in a newer (e.g., Portugal) or an older democracy (e.g., England). ${ }^{1}$ Overlapping the length of a nation's democratic experience

\footnotetext{
${ }^{1}$ Older democracies include Belgium, Denmark, France, Great Britain, and The Netherlands. Newer democracies include Greece and Portugal. The reference category includes Ireland, Italy, and Spain. See also note 8 .
} 
is the overall wealth of a country. At the individual level we may expect to see wealthier people more actively engaged with democratic politics, because they may have the economic interests, time, or resources to do so. Analogously, we might expect to see that wealthier nations provide a social context that facilitates higher levels of political engagement.

Other cross-national differences may also shape the impact of group membership. Studies of the consensus democracies argue that formal political institutions incorporate people into politics and may build civic virtue from the "top down" (Anderson and Guillory 1997; Lijphart 1999). They stress that formal political incorporation via consensual politics generates participation and also satisfaction with democracy. In some nations political incorporation of groups is statesanctioned and formalized to the point of hierarchical, corporatist arrangements. In others, social groups compete for influence in a more informal, pluralistic arena. The terms "corporatism" and "pluralism" are not only markers for distinct versions of democracy, but they also provide quite different examples of associational relations that affect how some group memberships, most notably in labor unions, are shaped by formal political institutions. We suggest that membership in some voluntary nonpolitical groups in a corporatist nation might not be as relevant in facilitating political engagement, if only for the fact that the nation's formal political institutions might play a larger role in doing this.

Similarly, the individual-level impact of church-group membership and specifically of denomination noted by Verba, Schlozman, and Brady (1995) may well vary by the nation's religious context. European states are distinct from the United States in often having dominant religions: broadly speaking, Catholic in the south, Protestant in the north. In some cases this dominance is reflected in the status of being a state church. As with groups in corporatist states, membership in church groups in Europe may involve ties to the wider political structure. Moreover, if membership in Protestant churches in Europe is associated with greater levels of voluntary activity, as in America (Verba, Schlozman, and Brady 1995, 320-25), then models estimating political engagement as a function of group activity need to control for national religious context.

European democracies thus provide interesting cases in which to see if national-level context shapes and conditions the impact of group memberships. With the models specified below, we can test how national-level and individuallevel variables affect political engagement.

\section{Hypotheses, Data, and Measures}

We assess the following questions: do voluntary organizations engender civic virtues, and if they do, what sort of groups are best for generating them? As Newton (1997) and Hooghe (1999) point out, these questions have not been welltested empirically, and any statistical tests will ultimately be unable to establish exactly what the direction of the relationship may be. Still, testing the theory with available cross-sectional data advances our understanding of the role that group 
membership has in democratic societies. Data for our analyses are taken from Eurobarometer 34.0, conducted in November of 1990. This survey not only provides responses to appropriate questions of political engagement and participation, but also asks respondents about their activities in social groups. This survey thus provides a reasonable data set from which to assess the questions at hand across a wide range of national settings. ${ }^{2}$

Responses to four questions were combined to create a single index reflecting an individual's engagement with democratic politics. We combine measures of how frequently the respondent discusses politics with friends, whether an individual tries to convince others of their views, how interested the individual is in politics, and whether the individual is a member of a political party. ${ }^{3}$ Table A1 in the online appendix presents a fuller description of the index. Each of these measures - taken individually - is unlikely to capture all aspects of political engagement. As an index, however, they do tap into a relatively broad range of participatory behavior and political engagement. If membership in informal, nonpolitical groups has an effect on engagement, we would see a significant association between group membership and this measure in models that control for other individual-level and national-level forces operating on engagement. ${ }^{4}$

The key independent variables of interest are group memberships. Information about nine different kinds of group membership is available in this survey, including church groups, unions, and other groups. ${ }^{5}$ Some of our measures of volun-

\footnotetext{
${ }^{2}$ Listwise deletion of cases with missing scores resulted in final samples of about 1,000 observations in each of 11 nations (see Table A2 in the online appendix for descriptive statistics on the distribution of the dependent variable in each nation). The original data set includes adequate samples for 12 nations. Norway is excluded here because some attitudinal measures are lacking for that nation.

${ }^{3}$ To measure attempts at convincing others (ICPSR study 9576, V69), respondents were asked "when you hold a strong opinion, do you ever find yourself persuading your friends, relatives or fellow workers to share your views? Does this happen: often [coded 3], from time to time [2], rarely, never [1]?" For frequency of discussion (V70), "when you get together with friends, would you say you discuss political matters frequently [2], occasionally [1], or never [0]?" For interest (V75), they were asked, "to what extent would you say you are interested in politics? A great deal, [3] To some extent [2], Not much [1], Not at all [0]?" For membership in a party (V61) see wording in footnote 5 below. Each item is standardized and weighted equally in our index which is the sum of these four terms. The resulting Cronbach's alpha is .61. See Table A1 in the online appendix for more details about reliability and covariation among items in the index.

${ }^{4}$ We also estimated models taking each of these measures as a separate dependent variable. Results are displayed in the online appendix. Use of this index also makes the presentation of our results much more parsimonious. Tables $\mathrm{A} 4 \mathrm{a}-\mathrm{A} 4 \mathrm{~d}$ of the online appendix provide models estimating responses to each of the 44 items, in each of the 11 nations (i.e., 44 separate models). In addition these tables also include estimates using the pooled sample from all nations to estimate logistic and ordered logistic regression models of individual items in the index. Results from these estimations do not challenge the substantive results presented in this article.

${ }^{5}$ Respondents were asked "which, if any, of the following groups or associations do you belong to?" They were shown a card listing the following, and multiple responses were permitted: charities, religious or church groups, cultural/arts groups, trade union or professional association, human rights organizations, nature conservation/ecology groups, youth groups, consumer groups, sports club or associations, or "other specific groups." See ICPSR study 9576 variables 57-66.
} 
tary social group membership in particular-those associated with membership in arts, charity, church, sports, and youth groups-are of special interest since these are not as obviously "political" as most of the other types of groups measured here. We test the hypothesis that membership in voluntary groups has a positive association with political engagement even after we control for individual-level factors associated with engagement. Further, the social capital literature leads us to expect this hypothesis will hold across all types of groups, for both obviously "political" groups (human rights groups, environmental groups) as well as the not so obviously political informal groups identified by the Tocquevillians as being important (arts and sports clubs in particular).

Although a strict reading of the social capital literature leads us to expect this hypothesis to hold across different nations, we anticipate that the effects of group membership might be greater in pluralistic states since formal incorporation of interests may mute the independent effects of group membership in corporatist nations. We test for this possibility by including terms that represent the effects of interactions between an individual's membership in a group, and her nation's level of interest group pluralism (IGP). ${ }^{6}$

Demographic and attitudinal factors at the individual-level also affect political involvement and engagement, and must, therefore, be controlled for in our models. Measures of educational attainment, gender, income, class, age, nonrural residence, religion, and perceptions of financial well-being (during the last year) are all included as control variables in the models. Categorical measures of these allow us to see any nonlinear effects associated with these variables. Religion is coded with three dummy variables for Catholics, Protestants, and other religions, respectively. The reference category for religion is those who did not categorize themselves in terms of any particular faith. For age, the reference group is 45-54, the high point of civic engagement over the life-cycle, and for income the reference group are those who replied "don't know or refused to answer." The reference group for perceptions of finances are those who felt their situations had not changed over the last year, and the reference category for education are those with the lowest levels. Working-class individuals are represented by a dummy variable reflecting self-identification. Our general assumptions are that the independent effects of nonrural residence, higher education, higher income, being nonworking class, being Protestant, and perceiving that personal finances have improved, will each be associated with higher levels of engagement.

Our estimates also account for whether the respondent was on the winning or losing side in the last national legislative election in their nation, since those backing losing parties can be more likely to be disengaged from politics (Anderson and Guillory 1997; Listhaug 1998). Respondents counted as being on the

\footnotetext{
${ }^{6}$ See Lijphart $(1999,171-84)$ for extended discussion of this measure and its correlation with a "consensus" model of democracy. Higher scores reflect more pluralism, low scores more corporatism.

${ }^{7}$ Interpretation of this reference is less intuitive than the others, but it allows us to retain respondents who refuse to disclose their incomes.
} 
losing side are those who did not vote for the parties that formed government after the recent election. We also control for the relative extremity of one's political views: an individual who self-identifies as either quite left-wing or quite right-wing is likely to be more engaged in politics than someone who does not see herself in such terms. We represent this by folding the standard left/right selfplacement scale into a single measure reflecting self-placement at either extreme.

Further, those with the most ideological views who support parties that are out of power may well be even more engaged with politics, since they may be relatively more politically sophisticated while also having grievances with the political order. We capture this with a term interacting our measure of ideological extremity with the measure of having been a recent "loser" in the electoral arena. In addition we included a measure of post-materialism and the standard left-right conservativism scale from which the extremism score was constructed. We also include a count of the total number of groups to which an individual belongs as another control. By including all of these factors affecting political engagement, we can be more confident that any correlation we observe between group membership and engagement is nonspurious.

The discussion above highlights national-level factors that could affect a citizen's engagement, if not condition the effects of various individual-level factors. Interest group pluralism (vs. corporatism) in each nation is measured by Lijphart's index (Lijphart 1999, 177). This measure ranges from high and positive for pluralist cases to nearer zero for the more corporatist cases. Other nationallevel variables in the models represent older and newer European democracies and a measure of each nations' per capita income. ${ }^{8}$ We expect that individuals in newer and poorer democracies will see generally lower levels of political engagement as a consequence of living in societies with fewer democratic resources.

We also included a variable representing each nation's religious context by including a measure of the percentage of the overall population who are Catholic. Extending the finding of Verba, Schlozman, and Brady (1995) from individuals to the national level, we expect to see predominantly Catholic states exhibit generally lower levels of political engagement. Alternatively, where Catholics are closer to majority or plurality status in a nation, religious homogeneity may lead some Catholics to be more engaged with politics. We include interactions between an individual's religion and her nation's religious context (measured as percent Catholic) to test for this. ${ }^{9}$ Finally, we control for the effect of high religious attendance for Protestants and Catholics, respectively.

\footnotetext{
${ }^{8}$ The age of democracy category measures the aggregate democratic experience that citizens might have in each of these nations at the time of the 1990 Eurobarometer survey. Old democracies are defined as those having age cohorts who may have experienced democratic elections prior to WWII. These include Belgium, Denmark, France, Great Britain, The Netherlands, and West Germany. Newer, post-WWII democracies include Greece and Portugal. Our results do not change when Spain is moved from the reference category to the new democracy category.

${ }^{9}$ Table A3 in the online appendix displays correlations among the national-level variables used here.
} 


\section{Model Specification}

Our hypotheses combine to model political engagement as a function of factors at two different levels of analysis: the individual and the national. The main hypotheses concern the individual-level effects of group membership after controlling for other individual-level attributes and national-level contextual effects on individuals. One way to address the effects of national attributes is by using hierarchical linear modelling, or HLM, a modelling technique designed to isolate such contextual, cross-system differences (Bryk and Raudenbush 1992). HLM is used to generate simultaneous estimates of the individual-level equation's parameters while allowing national differences in both slopes and intercepts. ${ }^{10}$

One way of thinking about HLM is that, in order to obtain estimates of the impact of second-level (national) effects on individuals (in this instance the impact of interest group pluralism, age of democracy, GNP per capita, and percentage Catholic), we perform a regression estimation at the individual level of a model along the lines of Equation (1).

$$
\begin{aligned}
\mathrm{Y}_{\mathrm{ij}}= & \beta_{0 \mathrm{j}}+\beta_{1 \mathrm{j}} \text { member union organization }_{\mathrm{ij}}+\beta_{2 \mathrm{j}} \text { member sports group }_{\mathrm{ij}} \\
& +\beta_{3 \mathrm{j}} \text { member church group }_{\mathrm{ij}}+\beta_{4 \mathrm{j}} \text { member charity }_{\mathrm{ij}} \\
& +\beta_{5 j} \text { member arts group }_{\mathrm{ij}}+\beta_{6 \mathrm{j}} \text { gender }_{\mathrm{ij}} \\
& +\beta_{7 \mathrm{j}} \text { college education }_{\mathrm{ij}}+\cdots+\mathrm{r}_{\mathrm{ij}}
\end{aligned}
$$

Here $\mathrm{Y}$ is the dependent variable for individuals (i) expressed as deviation from the mean of each country ( $j)$, and it is modelled as a function of membership in groups plus some other attributes (here gender and education); $r$ is the error term that expresses residual variation of individuals' scores from the mean of their nation and becomes especially relevant in calculating measures of fit. In HLM we can go further and model both intercepts $\left(\beta_{0 \mathrm{j}}\right)$ and slopes $\left(\beta_{1 \mathrm{j}}\right)$ as nation specific. The coefficients of the "random coefficients" regression model $\left(\beta_{0 \mathrm{j}}\right.$ and $\left.\beta_{\mathrm{ij}}\right)$ in Equation (1) serve as the dependent variables in simultaneous group-level regression estimates. So, for example, we might think that there are significant differences between nations according to both the degree of formal group membership (IGP, the corporatist-pluralist continuum) and the position of the Catholic church, e.g.,

$$
\beta_{0 \mathrm{j}}=\gamma_{\mathrm{q} 0}+\gamma_{\mathrm{q} 1} \mathrm{IGP}_{1 \mathrm{j}}+\gamma_{\mathrm{q} 2} \% \text { Catholic }_{1 \mathrm{j}}+\mathrm{u}_{\mathrm{qj}}
$$

Equation (2) models differences in the intercept in Equation (1) as a function of national level variables, here a nation's IGP score and the share of the overall population who are Catholic. We can also model second-level (here national) differences in the size of the parameters in Equation (1). In which case we might see the parameter associated with, say, membership in a labor union amplified by the role of unions in a more pluralist country, e.g.,

$$
\beta_{1 \mathrm{j}}=\gamma_{\mathrm{qj}}+\gamma_{\mathrm{q} 1} \mathrm{IGP}_{1 \mathrm{j}}+\mathrm{u}_{\mathrm{qj}}
$$

${ }^{10}$ Calculations were performed using HLM 5 (Raudenbush et al. 2000). 
The right-hand side variables in Equations (2) and (3) are "second-level" effects measured at the national level while $u$ is the error term for the second level (and, as with " $r$ " from Equation (1) becomes important in calculating goodness of fit measures below) . Equation (2) allows the adjusted mean of the individual-level dependent variable to differ from one nation to another and for these differences to be modelled. Equation (3) allows the effects of independent variables on dependent variables at the individual level (e.g., the effect of being a member of an arts group on the dependent variable) to differ from one nation to another and for these differences to be modelled.

In the results that are reported in Table 2, two models are estimated. Model 1 contains only effects of national-level covariates on means (that is, there are no covariates as in Equation 3), whereas Model 2 is specified such that effects of covariates on the slopes of independent variables are included. Although HLM models are relatively complex in that they operate at two levels of analysis simultaneously, the interpretation of regression coefficients is very much the same as in any other linear regression. That is, coefficients express effects of unit changes (or group differences from a reference category in the case of dummy independent variables) on outcomes (either means or slopes).

Using the impact of pluralism (as measured with the nation's IGP score) as an example, one question of interest is not just whether there are differences in political engagement between pluralist and nonpluralist states (i.e., a version of Equation 2) but also to see whether, for example, the impact of particular types of group membership vary across nations (a version of Equation 3). And so, conceptually, we can take the parameter associated with the impact of group membership on individual political engagement (Equation 1) and see if the size of this parameter varies across pluralist and nonpluralist states (Equation 3). The flexibility of HLM means that we can do this for a number of second-level effectsincluding age of democracy, religious context, and aggregate levels of wealth -at the same time, in order to look for intercept shifts.

HLM cannot demonstrate causality, but it provides a more rigorous test of association than standard regression models. Although we cannot sort out selection effects with this approach, a key hypothesis here is that, after controlling for both individual-level effects and also cross-national effects, we should see a positive correlation between political engagement and membership in nonpolitical groups if the neo-Toquevillian thesis can be generalized across all nations and all types of groups.

\section{Results}

Table 2 presents results of HLM estimates of our models for the primary variables of interest. These estimates were generated with models that also included additional control variables. Coefficients for the additional attitudinal and demographic controls are listed in Table 2A at the end of this article. The two left-most columns in Table 2 and Table 2A are estimates of equations of the type (1) and 


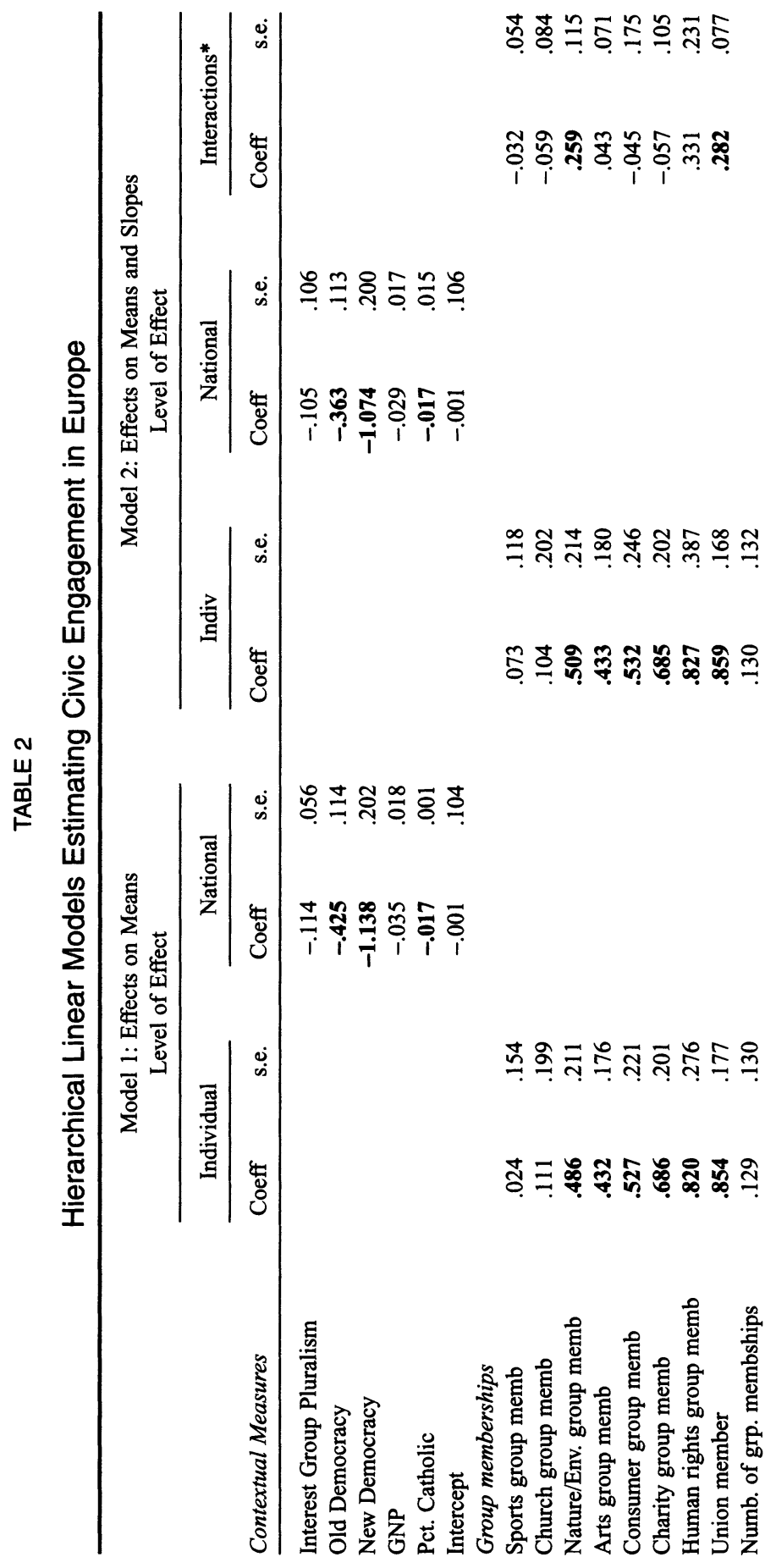


范

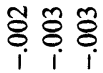

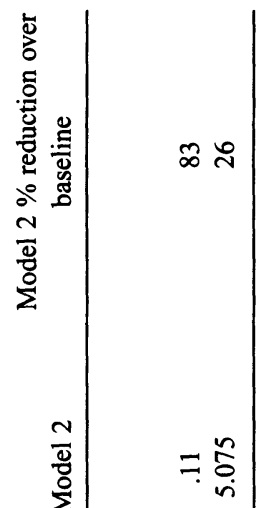

ธี :

ซ

$\Xi$

幽

焉

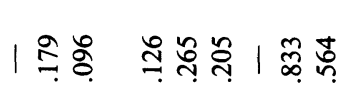

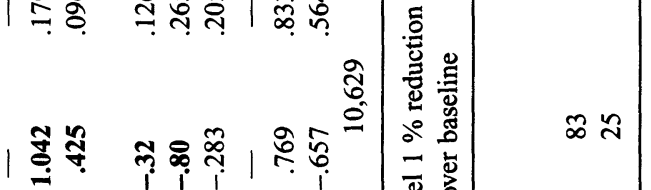

苋

¿

ธี ญ

일

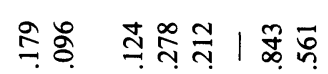

|

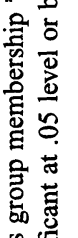

艛

幽

\section{.}


(2), while columns 3,4 , and 5 report estimates that includes the kinds of effects represented in Equation (3) above.

There are two sets of coefficients to discuss associated with Model 1 and three sets to discuss associated with Model 2. Model 1 produces coefficients representing individual-level and national-level effects on individuals, while Model 2 produces coefficients that reflect individual-level effects, national-level effects, and the effects of cross-level interactions. By and large most kinds of group membership are associated with higher levels of political engagement. The two notable and consistent exceptions to this are sports and youth groups. ${ }^{11}$

This is an interesting finding since these are the groups identified in the neoTocquevillian literature as needed to promote political engagement. The null association between sports groups and engagement can be seen in both of the HLM models in Table 2, and in nation-specific logistic regression estimations where each item from our engagement measure was used as separate dependent variables (these estimates are available in the online appendix, Table A4). Although it seems clear that most memberships are associated with increased engagement, not all groups are equally important. Groups that might be seen as overlapping with the political arena (environmental groups, consumer groups, unions, and human rights groups) are all associated with higher engagement. Of the groups that are of greater interest to neo-Tocquevillians - the relatively nonpolitical voluntary groups - charities and arts groups have much stronger associations with political engagement than church and sports groups. ${ }^{12}$

This pattern of group membership effects stands up, even after accounting for national-level contextual effects. The second column of Table 2 shows the results for the national-level effects as estimated via Model 1. Here we see several patterns of note. The first is that level of interest-group pluralism with a countryour measure of the lack of formal, corporatist group incorporation - has no direct impact on an individual's overall level of political engagement. The national-level effect of Catholicism mirrors the individual-level findings reported by Verba, Schlozman, and Brady (1995), even after controlling for wealth effects both at the individual-level and nationally. Respondents from nations with more Catholics have lower levels of engagement. Finally, individuals from countries that had little experience with democratic elections until after WWII-nations where democratic resources are likely to be sparse-had the lowest levels of polit-

\footnotetext{
${ }^{11}$ Use of the number of group memberships as a variable introduces linear dependence as it is the sum of all group memberships. This requires that one of the group membership measures must be omitted-we omit youth groups. When it is included without the measure of total group memberships, it is not significant.

${ }^{12}$ Any specification we used produced weak results for the effects of sports groups on civic engagement, relative to the effects of other groups. As the online appendix illustrates, there is some evidence that membership in sports groups is associated with one element of our civic engagement measure (interest: for Denmark, France, and Ireland). In no nation is sports-group membership associated with more than one item from our dependent variable. Moreover, the effect of membership in sports groups is associated with significantly less engagement in some estimations.
} 
ical engagement. Contrary to expectations, respondents from the older democracies had lower levels of engagement than those in "middle-aged" democracies. ${ }^{13}$

There are also other significant individual-level effects on political engagement, in addition to the effects of membership in groups. Recall that we do not assume that effects of all individual-level variables are likely to be linear. Hence, we break down education into several different categorical variables measuring, for example, medium- and high-levels of education. Even though there are positive effects for a moderate education level, the effects for higher education (university-level graduate or university student) are greater with a parameter roughly twice as large (the HLM estimates of Table 2 and Table 2A can be compared directly as in OLS).

A similar effort to capture possible nonlinearity is seen in our estimation of the effects of age, income, and perceptions of personal finances. Of these, age in particular displays nonlinearities suggestive of a life-cycle effect-people in the youngest and oldest age categories are significantly less engaged with politics than those in the reference group (45-54). Other demographic variables are associated with greater engagement. The independent effects of being male, an urban resident, nonreligious (the reference category for the individual-level religion variables), perceiving personal finances as most improved, and being in the top income bracket, are each associated with higher scores on our measure of engagement. We also find that citizens with relatively extreme ideological orientations are more engaged with politics, while people who rate themselves as relatively more conservative are less engaged.

Model 2 (Columns 3, 4, and 5) displays the individual-level effects of group membership estimated as functions of national-level variables. Model 2 builds on the results of Model 1 in two ways. In Model 2 we examine if formal corporatist arrangements at the societal level amplify or mute the impact of individual membership in voluntary organizations. Similarly, this model tests if the impact of religious affiliation is shaped by the wider religious environment: members of a church could, for example, behave differently when their denomination is in a minority within a society than when it is in a majority.

We can see in column 3 that the individual-level effects of group membership hold up when we account for cross-level interactive effects associated with pluralism and the nation's religious context. Results in column 5 (the group*IGP interactive effects) demonstrate that pluralism —or the lack of corporatism - conditions how membership in some groups is associated with engagement. Pluralism is associated with higher levels of engagement among union members and members of environmental groups. That is, in nations that lack formalized incorporation of groups, the effects of these memberships on political engagement are even more pronounced. In general, however, the effects of involvement in groups on an individual's engagement with democratic politics is typically direct and

\footnotetext{
${ }^{13}$ Again, see note 8 . The reference category includes Ireland, Italy, and Spain.
} 
does not usually depend on the degree of pluralism or corporatism of the national system. $^{14}$

Second, the cross-level interactions between an individual's religion and national religious context (Relig. * \% Catholic) illustrate that Catholics have lower levels of engagement regardless of the percentage of Catholics in a nation. Contrary to our expectations, Protestants are the least engaged-regardless of whether they reside in a predominately Catholic nation or not.

The goodness-of-fit for models of this type is assessed by examining the residual variation at both the individual-level (that is, how much of the variation of individuals from their nation's means is not explained) and the national-level (that is, how much of the variation in national means is not explained by compositional differences in the samples from different nations and the measured national-level differences). One of the virtues of HLM is that it helps to see where the main variance is to be explained-either at the individual or aggregated-level. Table 2 lists a baseline model fit with none of the national-level measures included that has a residual variance of 6.81 ( from $r$ in Equation (1) above) within nations and 0.63 between nations. This suggests that most of the variance is at the individual rather than national level. Furthermore by comparing the reduction in variance of the two models we can see the impact of the second-level variables. Model 1, the model with national covariate effects on means, but no national effects on individual-level parameters, accounts for $25 \%$ of the withinnation variance and $83 \%$ of the between-nation variance. Model 2 helps account for slightly more $(26 \%)$ of the within-nation variance. Nonetheless, the modelling of national-level effects does show significant impacts on the way in which political engagement takes place with some (modest) evidence of an amplification of political engagement by the presence of formal group arrangements in society.

\section{Conclusion: Bowling Together Might not Matter so Much as Singing Together}

Our analysis has shown evidence consistent with the argument of Putnam and the neo-Tocquevillians. That is, we see individual-level evidence that membership in some private, nonpolitical associations is associated with greater political engagement in Europe. This suggests that activity in such groups may generate democratic virtues. The nature of the group membership matters, however. Having said that, we ought to note that some of our findings are not consistent with the Putnam/neo-Tocquevillian arguments. Of the relatively nonpolitical, noneconomic groups expected by neo-Toquevillians to be breedinggrounds for democratic virtues (arts, charities, church, sports, and youth groups), only arts and charities are associated with political engagement. To a lesser extent,

\footnotetext{
${ }^{14}$ Although in other estimates-not reported here-it does have an impact on satisfaction with democracy in a manner entirely consistent with Anderson's findings (Anderson and Guillory 1997).
} 
national-level conditions may also affect how group membership is associated with engagement.

Of course, correlation cannot establish causation, but the lack of association between membership in some of these groups and political engagement leads us to question how far we may generalize about the "educative role" that all voluntary groups play in teaching democratic virtues. If voluntary groups play such a role, it would seem that not all are the same in their ability to do so. In other

TABLE 2A

HLM Estimates of Civic Engagement, additional controls used in models in Table 2

\begin{tabular}{|c|c|c|c|c|}
\hline \multirow{2}{*}{$\frac{\text { Attitudinal measures }}{\text { Conservative (scale) }}$} & \multicolumn{2}{|c|}{ Model 1} & \multicolumn{2}{|c|}{ Model 2} \\
\hline & -.064 & .026 & -.064 & .025 \\
\hline Strong ideology & .283 & .053 & .283 & .053 \\
\hline Supported Losing Party & -.058 & .127 & -.060 & .127 \\
\hline Str. ideology*Loser & .089 & .073 & .089 & .073 \\
\hline Finances much better & .588 & .196 & .590 & .195 \\
\hline Finances better & .201 & .070 & .201 & .071 \\
\hline Finances same & - & - & - & - \\
\hline Finances worse & .213 & .106 & .213 & .107 \\
\hline Finances much worse & .060 & .227 & .055 & .227 \\
\hline \multicolumn{5}{|l|}{ Demographics } \\
\hline Female & -.619 & .071 & -.618 & .071 \\
\hline Married & .126 & .072 & .127 & .073 \\
\hline Homeowner & .033 & .067 & .031 & .067 \\
\hline Top income group & .422 & .142 & .426 & .142 \\
\hline High income & .198 & .122 & .202 & .123 \\
\hline Medium Income & .074 & .107 & .080 & .106 \\
\hline Didn't reveal income & - & - & - & - \\
\hline Working Class & -.427 & .085 & -.427 & .085 \\
\hline High Education & .823 & .107 & .827 & .107 \\
\hline Medium Education & .454 & .073 & .455 & .073 \\
\hline Student & .852 & .170 & .854 & .171 \\
\hline Low Education & - & - & - & - \\
\hline Age $15-25$ & -.465 & .160 & -.466 & .161 \\
\hline Age $25-34$ & -.308 & .120 &.- .307 & .120 \\
\hline Age $35-44$ & -.105 & .096 & -.105 & .096 \\
\hline Age $45-54$ & - & - & - & - \\
\hline Age $55-64$ & -.082 & .106 & -.081 & .107 \\
\hline Age over 65 & -.263 & .138 & -.263 & .138 \\
\hline Town & .021 & .082 & .020 & .081 \\
\hline City & .088 & .104 & .087 & .103 \\
\hline Rural area & - & - & - & - \\
\hline
\end{tabular}

Note: Parameters in bold are significant at .05 level or better. A dash in place of a coefficient denotes the variable's reference category. 
words, choirs and theatre guilds may help pave the path to democratic virtue, but bowling leagues or football clubs may not. To the extent that this pattern holds up elsewhere this suggests the neo-Tocquevillians may have to develop more nuanced arguments with regard to the kinds of social groups that might instill democratic virtues.

While advancing our understanding of how groups may affect a citizen's engagement with democratic politics, this study also presents avenues for further research in this area. Our measures of group membership provide substantial variation across nations and types of groups, but they may mute the effects of some activity and also blur differences across types of groups inside each category. Future surveys with better measures of involvement in groups may better clarify how far neo-Tocquevillian arguments may be extended. This could include measures of time spent in activities associated with social groups. Research could be advanced further with better measures of various types of groups inside each of the categories used in this study. It is quite possible, for example, that not all sports groups are the same. Likewise, there might be substantial variation in the forms of group activity associated with what we categorize here as church or youth-group membership. It is difficult to imagine a nonexperimental social science research design that could provide the definitive test of causal relationships implicit in neo-Tocquevillian views on the effects of social groups on democratic virtues. Improved survey measures, however, could provide for additional tests of the relationships that we explored.

\section{Acknowledgement}

Additional appendix material can be found at: http://www.ac.wwu.edu/ donovan/art.html.

Manuscript submitted 30 April 2001

Final manuscript received 18 October 2002

\section{References}

Almond, Gabriel, and Sidney Verba. 1963. The Civic Culture: Political Attitudes and Democracy in Five Nations. Princeton: Princeton University Press.

Anderson, Chris, and C. Guillory. 1997. "Political Institutions and Satisfaction with Democracy: A Cross-National Analysis of Consensus and Majoritarian Systems." American Political Science Review 91(1): 66-81.

Arian, Edward. 1989. The Unfulfilled Promise: Public Subsidy of the Arts in America. Philadelphia: Temple University Press.

Barber, Benjamin. 1995. Jihad vs. McWorld. New York: Times Books.

Blandy, Doug, and Kristin Congdon. 1987. "Part III: The Citizen's Responsibility to Individual Group Problems.” In Art in a Democracy, eds. Doug Blandy and Kristin G. Congdon. New York: Teacher's College, Columbia University, pp. 34-59.

Booth, John, and Patricia Bayer Richard. 1998. "Civil Society and Political Context in Central America." American Behavioral Scientist 42(1): 33-46. 
Boyer, Barbara Ann. 1987. "Cultural Literacy in Art: Developing Conscious Aesthetic Choices in Art Education." In Art in a Democracy, eds. Doug Blandy and Kristin G. Congdon. New York: Teacher's College, Columbia University, pp. 78-99.

Brehm, John, and Wendy Rahn. 1997. "Individual-Level Evidence for the Causes and Consequences of Social Capital." American Journal of Political Science 41(3): 999-1023.

Bryk, Anthony S., and Stephen W. Raudenbush. 1992. Hierarchical Linear Models: Applications and Data Analysis Methods. Newbury Park, CA: Sage Publications.

Coleman, James. 1990. Foundations of Social Theory. Cambridge, MA: Belknap.

Eurobarometer 34.0. Perceptions of the European Community, and Employment Patterns and Child Rearing. October-November, 1990. ICPSR Study Number 9576.

Foley, M., and B. Edwards. 1996. "The Paradox of Civil Society." Journal of Democracy 7(1): 38-52.

Hooghe, M. 1999. "Voluntary Associations and Social Capital: An Empirical, Survey-Based test of the Putnam Hypothesis." Paper presented at the American Political Science Association meeting. Atlanta GA.

Kim, Sung Ho. 2000. "In Affirming Them, He Affirms Himself"-Max Weber's Politics of Civil Society." Political Theory 28(2): 197-229.

Lijphart, Arend. 1999. Patterns of Democracy. New Haven: Yale University Press.

Listaug, O. 1998. "Confidence in Political Institutions: Norway, 1982-1996." Paper presented at the Centre for Nordic Policy Studies, Aberdeen, Scotland.

Mansbridge, Jane. 1980. Beyond Adversarial Democracy. Chicago: University of Chicago Press.

Moyser, George, and Geriant Parry. 1997. "Voluntary Associations and Democratic Participation in Britain.” In Private Groups and Public Life, ed. J. van Deth. London: Routledge, pp. 121-34.

Newton, Kenneth. 1997. "Social Capital and Democracy." American Behavioral Scientist 40(5): 575-86.

$\rightarrow$ Norris, Pippa. 1996. "Does Television Erode Social Capital? A Reply to Putnam." Political Science and Politics 29(1): 474-80.

Pateman, Carole. 1970. Participation and Democratic Theory. Cambridge: Cambridge University Press.

Putnam, Robert. 1993. Making Democracy Work. Princeton: Princeton University Press.

Putnam, Robert. 1995. "Bowling Alone: America's Declining Social Capital.” Journal of Democracy 6(1): 65-78.

Raudenbush, Stephen, Anthony Bryk, Yuk Fai Cheong, and Richard Congdon. 2000. HLM 5: Hierarchical Linear and Nonlinear Modelling. Lincolnwood, IL: Scientific Software International.

Stolle, Dietlind, and Thomas Rochon. 1998. "Are All Associations Alike? Membership Diversity, Associational Type, and the Creation of Social Capital." American Behavioral Scientist 42(1): 47-65.

Tarrow, S. 1996. Making Social Science Work Across Space and Time: A Critical Reflection on Robert Putnam's Making Democracy Work." American Political Science Review 90(2): 389-97.

Verba Sidney, Kay Lehman Schlozman, and Henry Brady. 1995. Voice and Equality: Civic Voluntarism in American Politics. Cambridge: Harvard University Press.

Warren, Mark. 1992. "Democratic Theory and Self-Transformation." American Political Science Review 86(1): 8-23.

Shaun Bowler is professor of political science, University of California, Riverside, Riverside, CA 92521 (shaunb@citrus.ucr.edu). Todd Donovan is professor of political science, Western Washington University, Bellingham, WA 98225-9082 (donovan@cc.wwu.edu). Robert Hanneman is professor of sociology, University of California, Riverside, Riverside, CA 92521 (robert.hanneman@ucr.edu). 